\title{
Research on College English Teaching Time Allocation System
}

\author{
ZHAO Weihong ${ }^{1,}$,, XU Daoping ${ }^{1, b}$ \\ ${ }^{1}$ Qingdao Huanghai College, China

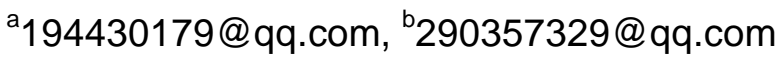

\begin{abstract}
Keywords: Awareness of efficiency; English teaching; multi-dimension; time allocation.
Abstract. On the premise of efficiency consciousness application, it has great significance to improve the efficiency of English learning by determining the value of College English teaching time distribution system for teaching quality. The time distribution management of English learning in China is discussed and analyzed on three levels via by comprehensive application of Historical document method and questionnaire survey method. The teaching time distribution management system is obtained through the multi-dimensional research, which can help the teachers set up a reasonable time concept and work with allocation strategy.
\end{abstract}

\section{Introduction}

College English is one of the most important courses in the education department over these years. In order to improve the teaching quality of College English, CET-4, CET-6 and the National College English Contest are set up at home. But there are still some problems in the English teaching resources in China at present, such as resource shortage, single teaching mode and the low efficiency of students' learning, etc [1]. Some educational institutions blindly pursue reform and innovation, leading to lacking the target intention in the teaching process. So far it has became one of the crucial problems to be solved in English teaching that teaching time is not proportional to the quality of teaching, time consuming and low efficiency is obvious. In this paper, based on the learning conditions of efficiency awareness, the effect on the efficiency of English teaching about reasonable allocation of teaching time will be studied.

\section{The Value of Time Distribution in English Teaching}

Education Methods. College English teaching is a very complicated and tedious task. Therefore, many scholars believe that as long as they obtain good education method, teaching time is not required to be distributed. However, the teaching time is a variable, and teaching behavior of teachers is affected by the energy and environment. In addition, students are more influenced by efficiency consciousness in the teaching process. For language learning, efficiency awareness is a potential and hidden influence factor. According to different student groups, it is required to improve the individual teaching level to achieve the high efficiency of classroom learning [2].

Analysis of the Efficiency Awareness Problem. Students should pay attention to the efficiency of learning, and the so-called efficiency awareness refers to the potential ability to make full use of time to enhance learning efficiency [3]. Several years' English learning cases can show that efficiency awareness of English learning can make students more interested in learning the content or knowledge in familiar fields and provoke a reaction against difficult and new knowledge. Under the influence of this condition, the allocation of teaching time will have an important effect on the students' efficiency consciousness. American education scholar Maurice is the first person who proposed the teaching idea, which can separate teaching and course and transform the task of teaching into concentration span of instructional time. He emphasized that the duration of attention is the key to the success of teachers' teaching. Carol, a famous American psychologist, brought up a subject that students' learning degree could be evaluated with time of quantization (the ratio of the actual time to the required time). According to the time model, it is found that the understanding of the teaching content and the ability of the students are all determined by the efficiency consciousness. It can be seen that the sense of 
efficiency in English teaching is an important factor that can not be ignored, and is closely related to the time factor

The Significance of Teaching Time Distribution. Reasonable allocation of teaching time means that the teachers can acquire greater teaching efficiency in unit time under the premise of adequate teaching hours, which is combining with the students' personal ability and professional characteristics. But the teachers can't go after progress in process of teaching alone, exactly so-called Haste makes waste, which requires teachers to arrange target tasks and methods properly and improve teaching efficiency and teaching quality steadily. In fact, this is also a permanent goal of college English teaching.

\section{Discussion on Management of Time Distribution}

Content Composition. Through the conclusion of research in classroom teaching, Stein, British scholar, pointed out that classroom study time is a multi-dimensional framework, affected by a variety of factors, such as school, society, family, etc. According to the situation of China, the time allocation management content has three aspects: national management, school management and teacher management.

National Management. College English is a public course stipulated by the State which can not be interrupted during the undergraduates, graduates, and postgraduates stages of education. It reflects and follows the country's demand for foreign advanced knowledge and culture. In order to guarantee the quality in the implementation process, the Ministry of education stipulated that the credit of college English should be more than $10 \%$ of the total credit. The level of English learning can be improved steadily through the basic, comprehensive English courses to the study of professional English courses. The state of English teaching and learning time indicated that China has attached importance to English learning policy and accepted laws of English learning. However, hours prescribed by the state are not effective time. Therefore, it is required to arrange the total hours scientifically, put the teaching efficiency in the first place, and maximize the effective time of the English teaching.

School Management. Distribution and management of English teaching time require the consideration and integration of the development of schools, the level of students, training objectives, professional requirements and other conditions. For example, based on the student's professional requirements, formulation of current English teaching hours, shows English curriculum model of "discipline" characteristics, but ignores the cross-subject teaching model, lacks of general education of curriculum, fails to represent integration of instrumentality and humanity [4]. English teaching process is relatively complex, which makes it more difficult for the school to carry out a more scientific period allocation of curriculum. According to the questionnaire survey, the allocation of time in English teaching is a process which needs continuous feedback to get optimum effect where it can be carried out on the basis of three steps: setting standard, measuring achievement and correcting deviations. Through the maximum utilization of school resources, it will gradually arrive at the gap with the expected goal and modifications.

Teacher Management. When carrying out English teaching tasks, teachers need to thin and screen the knowledge through their own serious teaching attitude and the personalized characteristics. With the development of computer technology and information technology, multimedia English in the classroom is more and more extensive, which makes the students' activities in the classroom more diversified and greatly helps enhance the students' sense of efficiency and then improves the quality of teaching [5].Although many colleges and universities devote a lot of energy toward English teaching, it 'can not meet the requirements of good teaching effect by increasing total hours alone. Instead, it can affect professional training because of reducing the amount of hours of other courses. Only through the management of teachers, it needs to be guaranteed for quality and efficiency of a single class hour to deal with the problem of English teaching hour. 


\section{The Construction of Time Distribution Management System}

Different Dimensionality. In this paper, the multi-dimension method is used to construct the college English teaching time distribution management system, which mainly includes three dimensions: state, school and teacher. The teacher's teaching management needs to be guided by national policy, completed by the school system planning. With a standardized system, it can improve English teaching quality and efficiency.

Dimension in Nation. Since 1980s, the Ministry of education of China has invested a lot of fund into English teaching, especially the construction of multi-media facilities. In policy, it mainly stipulates the teaching outline, the quantity, the teaching goal, the teaching quality assessment and so on. Although the country attaches great importance to the protection of English teaching hour, the total teaching hour is limited. The state has no relevant provisions on the selection of textbooks, the distribution of class hours, and the investigation of teaching objectives. Therefore, national dimension mainly shows function in guiding in whole system, which is the basis of the teaching time allocation and planning.

Dimension in School. School is the executor of teaching time allocation and the supervisor of teaching quality control, which mainly plays a connecting link role between the preceding and the following distribution of teaching time management system. The school needs to accept the guidance of national policy, absorb the English education policies and transform it into characteristic curriculum system, it also needs to supervise and guide the teacher's teaching task, so that English teachers can complete teaching objectives and requirements with great efficiency [6]. The school is the top-level agency of formulating specific distribution of teaching time, which also is required to fully investigate and analyze target amount of teaching task, and reduce dispersion of time utilization. In the paper, two mechanisms are put forward which are useful for school to establish mechanism of teaching time allocation, such as round robin system and through system. Among these functions, round robin system means that teachers are allowed to teach a class of students as far as possible, which can facilitate the understanding between teachers and students, and help teachers adjust teaching methods according to the situation of students, and improve students' awareness of efficiency. Through system means that a teacher is responsible for a single direction of English teaching, such as reading, writing, etc. Thus special training will reduce the waste of effective time.

Dimension in Teacher. The main function of teacher's dimension in time distribution system is to improve the efficiency of students and their teaching efficiency through optimizing the quality and efficiency of single class period. Although teachers can not change the total school hours and training schemes, but can accurately master the key points of teaching content and ensure rationality of the depth of learning. In single class, teachers are required to keep balance between school tasks and teaching progress. In teacher dimension, it proposes methods from three aspects to enhance the function of teachers' dimensions, such as spatial activity, media application and atmosphere adjustment. Among them, spatial activity means that teachers need help to shape good space order, and communicate with students in the form of activities to avoid time loss caused by the space order out of control. Media application means that teachers effectively use a variety of teaching methods to avoid time loss caused by latency of operations or failure. Atmosphere adjustment means fully mobilizing the tacit understanding between teachers and students in a limited period of time and improving dynamics of teaching.

\section{Model of research on system development}

In the research of professional development with its own resources, teaching, reflection, learning, research and cooperation are the most important core elements. Throughout the entire career of teachers, all these five factors influence each other, complement each other. Teaching has uppermost priority, and the teachers in the modern school teaching will learn to reflect, research, cooperate, and reflection, which will promote teachers' teaching in different aspects and different degrees. The best way for teachers to combine teaching and research to advance their professional development is to 
carry out action research in teaching. The best combination of teaching and reflection is reflective teaching. As a professional teacher with a more perfect professional theory and professional technical level, it needs a gradual process of development. Therefore, as with all the development of teachers, the professional development of teachers with their own resources will be phased. Generally speaking, it can be divided into embryonic period, exploration period, stable development period, rapid development period and stable development period.

\section{Conclusions}

Professional teacher development stage with its own resources is not fixed and immutable, and there are some certain differences which are depending on personal encounter. A teacher with a strong ability and an ideal opportunity might well develop from exploration period into rapid development period directly. Curriculum objectives can still reflect the basic requirements for the educational policy, which can predict some objectives and characteristics by the basis of the discipline, professional requirements, employment goals and social characteristics. The development of the professional field education can be realized rapidly during different dimensionality with the relatively modern talent in basic knowledge, ability goal, and quality requirements.

\section{References}

[1] Q.Q. Song: Education Science, Vol(2007)No.3,p20-23.

[2] ZH.J. Zhang, X.T. Huang: Psychological Science, Vol(2010) No.24,p50-54.

[3] L.W. Gu: Shanghai Education, Vol(2008)No.1,p26-28.

[4] A.D.Feng: Modern Educational Science, Vol(2005) No.2,p33-35.

[5] Sh.R.Wang, Ch.H.Yao: Chinese Foreign Language, Vol(2013)No.5,p4-10.

[6] R.Y. Li Ruiyu: Teaching and Management, Vol(2005)No.3,p10-11. 